\title{
DYNAMIC ASSESSMENT OF WORD DERIVATIONAL KNOWLEDGE: TRACING THE DEVELOPMENT OF A LEARNER
}

\author{
Dmitri Leontjev
}

\begin{abstract}
The present paper reports on a case study that explored the applicability of dynamic assessment (DA) for promoting learners' word derivational knowledge in English as a second or a foreign language (L2). One learner's performance on tasks assessing his word derivational knowledge was measured four times. The first two measurements were conducted before and after three weekly humanmediated DA sessions and the last two, which took place a year and a half later, before and after three weekly computerised DA sessions. Think aloud protocols and interviews were used to trace changes in the learner's use of strategies and knowledge sources. The results revealed that following the dynamic assessment, the learner improved his performance and used strategies and knowledge sources more successfully. The findings have implications for designing dynamic tests of L2 English word derivational knowledge and for word derivational knowledge instruction.*
\end{abstract}

Keywords: L2 learning, sociocultural theory, mediation, inferencing strategies, knowledge sources, self-regulation, English

\section{Introduction}

Word derivation presents a problem to learners of English as a second or a foreign language (Friedline 2011, Schmitt, Meara 1997). However, not much research on the acquisition of word derivation in English as a second or foreign language (henceforth L2) has been conducted. What is more, even less has been done as regards the way theoretical research findings can be applied in the L2 English classroom (Friedline 2011).

Nakayama (2008), for example, found that systematic teaching of prefixes to Japanese learners of English was more effective for learning vocabulary than

* I am grateful to the participant in the study and would like to thank two anonymous reviewers for their comments 
unsystematic teaching, but only as regards immediate gains. The limitation of the study was that the author did not compare the groups prior to the intervention.

Friedline (2011) aimed at acquiring a better understanding of the construct of word derivational (henceforth WD) knowledge and the way it can be trained. He first established differences in performance on several word derivation tasks of native speakers of English and L2 English learners, as well as differences between the learners of different mother tongues (L1s) and levels of proficiency. He then investigated whether pushed output, that is, collaborative dialogue in which learners are directed to producing output (e.g., Swain 1998) would be more effective for improving learners' WD knowledge than simple input processing. Contrary to his hypothesis, there was no significant difference between the groups (although both improved their performance). He suggested that it could have been the influence of the novelty effect, i.e., novelty of information increasing the possibility of its long-term storage (e.g., Tulving, Kroll 1995) that outweighed the effect of the treatment. Finally, using the Activity Theory framework, Friedline studied how learners' beliefs, attitudes, and actions changed in the course of the study, finding that learners integrated morphology into their language learning strategies (LLS) repertoire.

These studies produced important insights into the ways learning of WD knowledge can be guided. However, a deeper understanding of how training promotes the development of learners' WD knowledge is required. The aim of the present study is to understand how dynamic assessment (DA), being a pushed output activity, directed one learner's performance and promoted his WD knowledge. Before presenting the study, I will outline some of the research on L2 English word derivation and learning strategies / learners' self-regulatory behaviour.

\section{Background}

\subsection{Research on L2 English word derivation}

Studies of L2 English word derivational knowledge are not numerous. However, some interesting findings have been produced. For example, evidence for its incremental development has been found (e.g., Schmitt 1998, Schmitt, Meara 1997). Following the developmental paradigm adopted in these studies, it is logical to assume that some affixes can be easier to learn than others. With this intention in mind, Bauer and Nation (1993) proposed a teaching order of derivational affixes based on a number of their morphological, phonological, and orthographical properties (Table 1).

Table 1. Affix difficulty order (Bauer, Nation 1993)

\begin{tabular}{|l|l|}
\hline Level 1 & A different form is a different word \\
\hline Level 2 & Inflectional affixes \\
\hline Level 3 & The most frequent and regular derivational affixes, e.g., -able, -er, -less, -ly, -ness, un- \\
\hline Level 4 & Frequent and regular affixes, e.g., -al, -ation, -ful, -ism, -ize, -ment, in- \\
\hline Level 5 & Infrequent but regular affixes, e.g., -age,-ship, mis-, etc. \\
\hline Level 6 & Frequent but irregular affixes, e.g., -ee, -ion, re-, etc. \\
\hline Level 7 & Classical roots and affixes, e.g., -ate, - -ure, etc. \\
\hline
\end{tabular}


While not much empirical evidence exists for the validity of the order, Leontjev (forthcoming), for example, found that for the most part (i.e., except for no significant difference between affix levels 5 and 6), the order holds as the order of difficulty learners have with recognising derivational suffixes.

In addition, a link between learners' L2 English WD knowledge and proficiency has been found (e.g., Leontjev et al. (forthcoming), Mäntylä, Huhta 2013). It appears that this link depends on the operationalisation of learners' WD knowledge. Friedline (2011) found that learners' proficiency seemed to relate to learners' performance on a word relatedness task (asking to indicate whether two words, e.g., productive-production, are related) although this assumption was not tested statistically. On the other hand, he did not find a relationship between learners' proficiency and their performance on lexical decision (asking to rate the certainty that presented derived words were real) and word decomposition (asking to write base forms of the presented derived words) tasks. Mäntylä and Huhta (2013) found strong correlations between learners' proficiency and their performance on affix elicitation tasks. Finally, Leontjev et al. (forthcoming) demonstrated that both syntactic and semantic knowledge of derivational affixes strongly predicted learners' writing proficiency.

However, the question still remains of how exactly derivational affixes should be taught. Friedline (2011) found that following the treatment, learners integrated morphology into their LLS repertoire, at the same time each still using their own array of strategies. This suggests that as learners become more self-regulated in the use of word derivation, they adopt new techniques to regulate their learning, as will also be outlined in the following section.

\subsection{Strategy use or self-regulatory capacity}

It has long been noticed that learners regulate their learning by using a number of techniques, and that self-regulatory capacity increases as their abilities grow (Dörnyei 2005). It is no wonder that considerable research has been conducted targeting language learning strategies (see, e.g., Dörnyei 2005 for a discussion). Based on the proposed LLS taxonomies (Oxford 1990, O’Malley, Chamot 1991), LLS can be divided into:

- metacognitive (planning the learning process);

- $\quad$ cognitive (manipulating the material to be learned);

- $\quad$ social/affective strategies (interacting with peers and adjusting one's beliefs, feelings, and emotions).

As Dörnyei (2005) noted, the LLS-based paradigm has several issues, including the fuzziness of construct definition, classifications of LLS, and methods of study. Instead, a shift from LLS (i.e., product) to self-regulation (i.e., process) was proposed. Tseng et al. (2006) designed an instrument aiming to tap into learners' self-regulatory processes in vocabulary learning. The instrument was a Likert-scale type questionnaire, its items falling into one of five facets:

- commitment control (helping to preserve learners' commitment to the original goal);

- metacognitive control (controlling the concentration on the task); 
- $\quad$ satiation control (eliminating boredom);

- $\quad$ emotion control (generating emotions that help to implement the goal, e.g., self-encouragement);

- environmental control (minimising negative and making use of positive environmental influences, e.g., asking friends for help).

However, as, for example, Rose (2012) argued, the model suggested by Tseng et al. (2006) is compatible with LLS-based models and they should rather represent parts of the same construct. Rose (2012) also urged for a more qualitative research of strategic learning.

Nassaji's (2003) study would have been difficult to conduct only within the paradigm suggested by Tseng et al. (2006). The author explored the relationship between learners' vocabulary inferencing strategies and inferencing success. Interestingly, the author, in addition to strategies, also considered knowledge sources, defining the strategies as cognitive or metacognitive actions used to understand the problem and/or overcome it and knowledge sources as references to particular sources of knowledge (e.g., phonology). Importantly, instead of a questionnaire, the author used think aloud protocols and interviews as data collection tools. The author found that while morphological knowledge had the highest rate of success, no one knowledge source or strategy alone resulted in successful inferencing, but rather combinations of these did. He concluded that it was not the quantity of strategies that mattered, but their quality.

It should be noted that Bowles (2010) found that thinking aloud can, in some cases, facilitate learning. However, as the author noticed, the results vary, and generally, the effect of thinking aloud as compared to silent thinking is small.

As regards strategy instruction, several studies (e.g., Kozulin, Garb 2002, Teo 2012) have been aimed at discovering whether mediating learners' strategies in dynamic assessment improved their abilities. Next, I will discuss these studies in some detail.

\subsection{Dynamic assessment of L2}

Dynamic assessment (DA) developed at the crossroads of assessment and instruction as an alternative to conventional assessment, which DA proponents often refer to as static assessment (SA). It builds on the Vygotskian concept of Zone of Proximal Development, which is

the distance between the actual developmental level as determined by independent problem solving and the level of potential development as determined through problem solving under adult guidance or in collaboration with more capable peers (Vygotsky 1978: 86).

Application of this concept to assessment resulted in a view that no assessment can provide a full picture of learners' development without incorporating their potential for development. In DA, this is achieved by providing guided support, known as mediation, which aims at both discovering learners' potential development and promoting their abilities (Poehner 2008). Mediation in DA is often operationalised by way of the number of feedback messages gradually becoming more explicit and 
detailed until learners are either able to self-correct their mistakes or are provided with the correct response (Poehner, Lantolf 2013, Teo 2012).

It has been demonstrated that DA is successful in promoting learners' L2 abilities (Leontjev 2014, Kozulin, Garb 2002, Poehner, Lantolf 2013, Teo 2012). Some of these studies reported on computerised DA (Leontjev 2014, Poehner, Lantolf 2013, Teo 2012). The advantages of the computerised modality include the possibility to assess several learners simultaneously. However, computerised DA is limited to an interventionist approach, in which mediation is standardised and is provided in a predefined fashion. Often, the dynamic part in interventionist DA is conducted between a static pre- and posttest (the so-called sandwich format; Poehner 2008). In contrast, in interactionist DA mediation emerges in interaction between the learner and the assessor. When learners' development within one or across several DA sessions is traced, transfer items, that is, items assessing the same feature, can be used to trace the increase in learners' abilities (Poehner, Lantolf 2013).

Some DA studies have an explicit focus on LLS. Kozulin and Garb (2002) studied the effect of mediating learners' LLS. The authors found that DA improved learners' reading comprehension. Unfortunately, they did not illustrate the actual mediation process, nor did they report on the learners' use of strategies following the DA.

Teo (2012) studied learners' LLS after a computerised DA. The author found that the computerised DA helped the learners to use a number of strategies appropriately, which, she argued, improved their inferential reading abilities. However, the author did not collect any data on the learners' LLS use before the DA.

\section{Methodology}

\subsection{Research question}

The previous research has produced important insights regarding learners' L2 English word derivational knowledge and the way dynamic assessment promotes the development of learners' abilities. The present case study aims at combining these two strands of research by finding answers to the following question:

- How, if at all, does dynamic assessment promote L2 English learners' ability to derive words?

The particular emphasis in the study will be on the way the participant regulated his learning prior to and following dynamic assessment.

\subsection{Participant and data}

The participant in the study was an L1 Russian learner (16 year old) studying English at grade 10 of an Estonian school at the onset of the study. Hereinafter in the paper, he will be referred to as $\mathrm{M}$.

Nation (2001) suggested that L2 word derivation instruction is beneficial to learners at lower-intermediate level, which is roughly equivalent to level B1 on the Common European Framework of Reference scale (Council of Europe 2001), the L2 proficiency that learners in Estonia are expected to achieve by grade 10 (Põhikooli 
riiklik õppekava õigusakt: Lisa 2, 2010). Moreover, the results of Leontjev et al. (forthcoming) suggested that learners' WD knowledge increases after level B1 is reached. Thus, the participant was selected among tenth-graders.

By the time of the study, $M$ had been studying English for about seven years. He also revealed that at school, he was occasionally taught word derivation, which reduced the possibility of the novelty effect due to the introduction of WD during the treatment.

The data come from a) M's performance on four computerised static assessment (SA) sessions, each consisting of seven tasks requiring $M$ to demonstrate different aspects of his WD knowledge, b) M's think aloud protocols collected when he was working on the first three items of each SA task, c) four interviews immediately following each SA session, and d) M's performance on three weekly human-mediated and three weekly computerised dynamic assessment sessions. The tasks were administered in an online tutoring/assessment system (see Leontjev 2014 for details). The procedure was the following:

1) two SA sessions, one preceding and one following three weekly humanmediated DA sessions, both SA followed up with an interview;

2) a year and a half gap;

3) two SA sessions, one preceding and one following three weekly computerised DA sessions, both SA followed up with an interview.

The decision to have a year and a half gap was due to a modest at best improvement in the knowledge of derivational affixes in the course of one academic year found by Schmitt and Meara (1997). Therefore, a larger gap was introduced to allow for a greater increase in M's word derivational knowledge. By the time of the third SA session, $M$ was at the end of grade eleven and was 17 years old.

A combination of think aloud protocols and research interviews was used to establish strategies and knowledge sources that M used during the SA (cf. Nassaji 2003).

The task types in the SA were:

- $\quad$ free production (form as many words as possible from the given words);

- metalinguistic prompts (form different parts of speech from the given words);

- non-word affix elicitation (complete the non-words in the sentences using the context and the explanations);

- prefix elicitation (complete the words in the sentences using provided prefixes);

- grammar recognition (complete the sentences selecting one option among those provided; same base, different affixes forming different parts of speech);

- meaning recognition (same as previous, but the options were the same parts of speech);

- passive meaning recognition (select the definition among those provided to the highlighted words in the sentences).

Sample items from the SA tasks are presented in Appendix. For further details on the tasks, see Leontjev et al. (forthcoming). No feedback on M's performance was given to him before the end of the final SA session. 
Both the human-mediated and the computerised DA were designed following the interventionist sandwich DA format (see Section 2.3). Based on the findings of Leontjev et al. (forthcoming), the mediation targeted M's use of syntactic or semantic knowledge of affixes, or both. The task types in the human-mediated DA were:

- $\quad$ classification exercises, e.g., which of these words are adverbs; what parts of speech are the rest of the words: momentary, literacy, ability, hyperactively;

- affix elicitation exercises, e.g., on the basis of the word in the brackets, form a word that fits the sentence: They want to raise ............ (aware) of the problem.

A multiple-choice task format was used in the computerised DA (Figure 1).

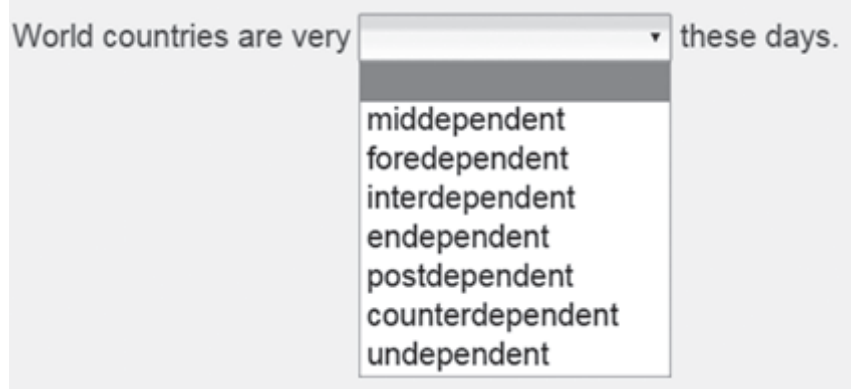

Figure 1. Sample item from the computerised dynamic assessment

The difficulty of the items was operationalised as Bauer and Nation's (1993) affix levels (Table 1). Generally, in earlier DA sessions, affixes at lower levels were used than in later sessions. However, several transfer items (i.e., different items with the same affixes) were included in later DA sessions to see if there was any progress in the use of these affixes. Thus separate higher-level affixes appeared in earlier DA sessions, and some lower level affixes were used in later sessions.

Desktop video recordings were made of M's SA performance. These were used during the interviews to help $M$ recall what he had been doing while working on the tasks. The human-mediated DA sessions were audio recorded. Detailed logs of M's performance on the computerised DA were recorded by the online system.

\subsection{Analysis}

To determine whether there was any progress in M's unassisted performance, his correct responses on the SA tasks were counted across the sessions. Then, the assistance $M$ required during the computerised and the human-mediated DA was compared across the DA sessions.

The video- and audio-recorded data were transcribed, coded, and analysed with the help of ATLAS.ti qualitative analysis software. The coding was done by two coders (the present author being one of them) independently, and then agreed upon in the cases where dissimilar decisions were made. The coding was inspired by 
Nassaji's (2003) list of strategies and knowledge sources, but, above all, the codes emerged from the analysis of the transcript (Tables 2 and 3 ).

Table 2. M's strategies

\begin{tabular}{|l|l|}
\hline Strategy & Description \\
\hline Repetition & repeating any portion of the text \\
\hline Verifying & checking the appropriateness of the response against the wider context \\
\hline Self-inquiry & asking oneself questions \\
\hline Analysing & analysing a word morphologically \\
\hline Monitoring & showing awareness of the problem or the difficulty of the task \\
\hline Analogy & drawing on similarities with other words \\
\hline
\end{tabular}

Table 3. M's knowledge sources

\begin{tabular}{|l|l|}
\hline Knowledge source & Description \\
\hline $\begin{array}{c}\text { Syntactic knowledge: } \\
\text { a) affixes } \\
\text { b) words }\end{array}$ & knowledge of syntactic functions of affixes or words \\
\hline $\begin{array}{c}\text { Semantic knowledge: } \\
\text { a) affixes } \\
\text { b) words }\end{array}$ & $\begin{array}{l}\text { knowledge of the meanings of the affixes or words (either translations } \\
\text { or definitions) }\end{array}$ \\
\hline Mother tongue/English & L1/L2 analogy \\
\hline
\end{tabular}

The strategies identified in the analysis of the transcript were classified as either cognitive (e.g., analysing) or metacognitive (e.g., self-inquiry). This is because social/affective strategies were generally not present during the SA, the exception being one use of a social strategy (5). Analogy is present in both tables since both coders agreed that the knowledge source for analogy (i.e., English or L1) had to be specified. Since except in the last three SA tasks, base words were given, with several exceptions (e.g., M recognising inter- in interactive in the metalinguistic prompts task in the last interview), the analysing strategy was identified in the last three tasks only.

In addition, in line with Vygotsky's (1978) sociocultural theory, not only the DA, but also the previous SA sessions, the interviewer's utterances, and what $M$ himself had previously reported mediated his self-reports. Therefore, each interview, think aloud protocol, and the whole data set collectively were also analysed holistically.

\section{Results}

First, I will demonstrate that M's performance improved across the static assessment sessions. Then, I will trace how M's use of strategies and knowledge sources changed in the course of the study. Finally, I will demonstrate how dynamic assessment facilitated these changes and how both the interviewer and M's own verbalisation of his thinking guided M's performance. 


\subsection{Improvement of M's performance}

Table 4 illustrates changes in M's performance. It should be noted that, as some of Bauer and Nation's level 2 affixes (e.g., -ing) can be both inflectional and derivational, I limited the figures to words formed with help of levels 3 to 7 (see Table 1). Although the number of base words in the free production task was 10, the number of words possible to form was not limited. In the metalinguistic prompts task, while there were 10 items, the total number of words possible to form was thirty.

Table 4. M's performance on the tasks across the four SA sessions

\begin{tabular}{|l|c|c|c|c|}
\hline & $\mathbf{1}$ & $\mathbf{2}$ & $\mathbf{3}$ & $\mathbf{4}$ \\
\hline Free production & 12 & 26 & 23 & 25 \\
\hline Metalinguistic prompts & 11 & 15 & 16 & 18 \\
\hline Non-word affix elicitation $\left(\mathrm{k}=10^{*}\right)$ & 4 & 7 & 9 & 10 \\
\hline Prefix elicitation $(\mathrm{k}=12)$ & 8 & 11 & 10 & 11 \\
\hline Grammar recognition $(\mathrm{k}=10)$ & 8 & 8 & 9 & 9 \\
\hline Meaning recognition $(\mathrm{k}=10)$ & 6 & 7 & 9 & $8^{* *}$ \\
\hline Passive recognition of the meaning $(\mathrm{k}=10)$ & 8 & 8 & 9 & 9 \\
\hline
\end{tabular}

* Three items containing Bauer and Nation's level 2 affixes were removed from the scale.

** Considering that M understood his mistakes in the task before the end of the test (see Section 4.4), the score can be raised to 10 .

The biggest increase in M's performance was between SA sessions 1 and 2. The computerised DA resulted in a smaller increase, which at least in one task can be attributed to the ceiling effect. There seemed to be little or no progress in the grammar recognition and passive meaning recognition tasks. However, as the qualitative analysis revealed, the way that $\mathrm{M}$ worked through the tasks (including the two tasks where there seemed to be no improvement) was different across the SA sessions (see Section 4.2). It is also interesting to note that during SA sessions 2 and 4, M correctly used several affixes (e.g., en-, -en, -ic, -ist) that were not trained in the DA. What is more, generally, $M$ required less help with the transfer items during the DA (see, e.g., Example 4 and the following discussion).

\subsection{M's strategies and knowledge sources}

Already during the first SA session, $\mathrm{M}$ reported using a number of strategies, as is exemplified in Example (1) (see Figure 2.6 in Appendix for a sample item) from the think aloud protocol (hereinafter in the transcript, interviewer $=\mathbf{I}$ ). I found that the English translation was sufficient for reporting on M's strategies and knowledge sources. Thus, the original Russian transcript will not be supplied. I will, however, note pauses, intonation, non-verbal behaviour, etc. I will supply line numbers in longer examples. Note that the parts that were originally in English are italicised. 


\section{(1)}

9 M: Because it is a verb (3.1) [opens the drop-down menu; looks at the 10 options] (6.8)

11 I: Continue (.) thinking.

12 M: Uf:: (4.2) terrify (4.2) terrify terrorise (5.6)

13 I: Speak out your thoughts.

$14 \mathrm{M}$ : I now think that terrify is an adverb (1.6) and terrorise is a verb (4.2).

15 I: The reason?

M: (4.1) Because terrorise has the ending (o.8) al es $i$ :, which is the ending of some verbs, for example, (0.4) rise.

From Example (1), it transpires that M used verifying (lines 1 and 5-6), repetition (lines 3 and 10), self-inquiry (lines 3 and 5), analysing (line 14) and analogy (line 15). These strategies (except for analysing) were common during the first SA, and some of them could have been beneficial for finding the correct response. However, this task required $\mathrm{M}$ to think about the meanings of derivational affixes, but he resorted to his syntactic knowledge. In fact, throughout the first SA session, M referred to semantics of affixes only seven times, often failing to do so even in the tasks that were difficult to complete correctly otherwise.

In the following SA sessions, $\mathrm{M}$ reported on the semantics of affixes considerably more, that is, fourteen, twenty-two, and thirty times respectively. Interestingly M's use of this knowledge source was slightly different after the human-mediated and computerised DA. The usual way M referred to this knowledge source after the human-mediated DA is exemplified in (2).

(2) M: Here we have two adjectives (3.8).

I: Right.

M: We:ll, -able means aptitude for something.

$\mathrm{M}$ first acknowledged that both options were adjectives and only then analysed one of the options, supplying the meaning of suffix -able. This pattern was rather frequent during the second SA. For example, in the meaning recognition and the passive recognition of the meaning tasks (where semantic knowledge was required), M used it seven times. M still used this pattern during the third SA four times.

However, the usual way $M$ worked through the meaning recognition and the passive recognition of the meaning tasks was different during the last SA (see Example 3 from the interview).

(3) I: Clarity. Why?

M: (2.2)

I: Why not clarification? 
M: Because it is a process.

I: Uhu. And clarity?

M: It's like (0.7) well, like a quality.

I: Right. Do you know these words or where did you- (.) or what (.) process, quality?

M: Well, suffixes.

That is to say, during the last SA session, $\mathrm{M}$ did not rely on syntactic knowledge in these two tasks.

In addition, during the first SA, M only occasionally tried to analyse the words (all in all, seven times) whereas in later SA sessions, this number increased to ten, fifteen, and nineteen times respectively. This is not to say that M used only one strategy / knowledge source to solve each item. On the contrary, in most cases, it was a combination of several of them, as Example (1) illustrates. For example, in the third SA, M often combined other strategies with knowledge of meanings of words, successfully using it all in all 30 times, as compared to 15 and 20 during the first two SA sessions respectively). This suggests that M's vocabulary knowledge increased, which can explain the improvement between SA sessions 2 and 3 (Table 4). Interestingly, after the computerised DA, M's use of this knowledge source decreased to 24.

It should also be noted that in later SA sessions, M's certainty in his responses increased, as manifested in the decreased frequency of using monitoring, repetition, and self-inquiry. The analysis of M's DA performance sheds more light on these changes.

\subsection{Dynamic assessment}

The way mediation was provided to $\mathrm{M}$ during the human-mediated DA is illustrated in Example (4) from the third DA session.

(4)

1 I: Look at the seventh

2 M: (5.2)

3 I: sentence. Which part of speech do we need to form? He is known

4 for $\uparrow$ hi:s-

5 M: Fearlessness-a noun.

6 I: Right. And what do you have?

$7 \quad$ M: Ah (o.6) an adjective.

8 I: Right. Something is missing. That is (.) you have the adjective 'fear-

9 less'. Which means $\uparrow$ what?

10 M: Fearless.

11 I: So, what you need to add is a suffix that makes it into a noun.

12 M: (4.0).

13 I: Think what the word means. What is fearlessness?

14 M: A quality.

15 I: Great!

16 M: (16.5) Fearnessless?

17 I: Yes, but vice versa.

M: ((laughter)) Fearlessness. ((laughter)) 
The interviewer, first, drew M's attention to the sentence with a mistake. He then elicited the syntactic function of the word and invited $M$ to use the context (line 3 ). While M established that a noun was required (lines 4-6), he was still hesitant as to which suffix to use, so the interviewer asked $M$ to think about the meaning of the word. That M first provided the meaning and then solved the item was not coincidental, as during the first human-mediated DA session, $M$ was explicitly told that the meaning of -ness was that of quality. This was but one example of $\mathrm{M}$ requiring less help with transfer items.

A difference between the human-mediated and computerised DA was that during the computerised DA, M never selected an option which was a wrong part of speech. Therefore, the mediation during the latter did not elicit syntactic functions of the affixes (Table 5).

Table 5. Performance log from a computerised DA session (English translation)

\begin{tabular}{|l|l|}
\hline Try & Mediation \\
\hline 1 & $\begin{array}{l}\text { Your answer: The reflectable surface of the lake shines in the sun. } \\
\text { Think more carefully. }\end{array}$ \\
\hline 2 & $\begin{array}{l}\text { Your answer: The reflectant surface of the lake shines in the sun. } \\
\text { Read your sentence carefully. Think what the suffix that we need can mean. Which suffixes } \\
\text { among provided do you think can mean it. }\end{array}$ \\
\hline 3 & $\begin{array}{l}\text { Your sentence: The reflectory surface of the lake shines in the sun. } \\
\text { Suffix -ory means serving for something or characterised by something. The suffix that } \\
\text { we need means doing something specified. }\end{array}$ \\
\hline 4 & $\begin{array}{l}\text { Your sentence: The reflective surface of the lake shines in the sun. } \\
\text { Correct. }\end{array}$ \\
\hline
\end{tabular}

As is demonstrated in Example (4) and Table 5, in both human-mediated and computerised DA the mediation did not explicitly instruct $\mathrm{M}$ to analyse the words, but still elicited this strategy. Depending on M's responses, the instruction to use specific knowledge sources varied in explicitness.

While, as has already been mentioned, $M$ generally required less help with transfer items, in a small number of cases $\mathrm{M}$ required more assistance with them. One such case was the suffix -ive, with which $\mathrm{M}$ required level 1 feedback during the first computerised DA session and level 3 feedback, during the third session (see Table 5). In both cases, M's first choice was suffix -able, which suggests that he was still not fully self-regulated in its use, as he was not in using the suffix -ive. This is also evident during the last SA session, as will be discussed in Section 4.4.

It should also be noted that $M$ required less help during the computerised DA as compared to the human-mediated DA.

\subsection{Mediation during the static assessment}

As mentioned in Section 3.3, the interviewer eliciting responses from $\mathrm{M}$ appeared to direct M's performance. One example of it was Example (1), where the interviewer was pushing $M$ to verbalise his reasons for selecting terrify, which was the 
correct response, but, as became apparent, was selected for the wrong reasons. As such, it was not a typical think aloud procedure, and it resulted in M selecting the incorrect option. This might be considered a negative influence of the interviewer's intervention, but in fact, it resulted in a more accurate representation of M's ability.

However, it was not just the interviewer who mediated M's performance. In Example (5) from the last SA session, M was thinking aloud while solving the item You must show demonstrative improvement of your work from the meaning recognition task.

(5) M: Here, it is again a difference in meaning. If you put demonstratable (.) it means that improvement is able to demonstrate itself. $\uparrow \mathrm{M}:(3.0)$ $\mathrm{m}$ : demonstrative (.) is demonstrative. (2.8) Here (.) it is ${ }^{\circ}$ demonstrative $^{\mathrm{o}}$ (6.1).

I: Right.

M: You know it, but I don't know. ((chuckle)) (4.0) I'm leaning towards $\uparrow$ demonstratable (3.2).

I: Right.

M: No, demonstrative ((chuckle)) (10.2) demonstrative.

Apparently, M was not sure which option was correct, as is manifested in his pauses, rising intonation, pronouncing the option demonstrative softly and quietly, acknowledging the interviewer as a master of the ability, and contrasting the latter's abilities with his own. Interestingly, in the following task (i.e., passive meaning recognition), M's performance on the item with -ible (suggestible) was different (6).

(6) M: [selects 'can be easily changed by others'] (3.1)

I: And how (.) why the third option?

M: I finally remembered this (.) after the third practice, the third time taking this test [actually, the fourth], I remembered (o.6) what suffix -able means. It means that the children are subject to be influenced. Well (.) that's the meaning (1.8).

I: $\mathrm{m}$ :

M: That is, it's not that they are able [to do something], but they are able to be influenced.

Without much thinking, $\mathrm{M}$ selected the correct option and produced a coherent explanation. What is more, during the interview which followed immediately after the SA session, M laughed when he saw the video recording of him working on the item (5) and told the interviewer that because he thought that -able had a different meaning, he actually made two mistakes in this task, one where he used -ive in place of -able and the other where he used -able instead of -ive. I will discuss this change with reference to self-mediation in Section 5.

\section{Discussion}

The present study endeavoured to find answers to (a) whether dynamic assessment (DA) can promote learners' L2 English word derivational (WD) knowledge and (b) how it can do so. 
The results confirmed that DA, both human-mediated and computerised, improved the participant's WD knowledge operationalised as his scores on static assessment (SA) tasks and his performance on transfer items. The increase in M's performance after the computerised DA was smaller, but considering the fact that after the computerised DA, M performed at the ceiling on the non-word affix elicitation (perhaps also meaning recognition) task and the fact that the difference between sessions 3 and 4 (i.e., due to the DA) was similar to or bigger than that between sessions 2 and 3 (between which a year and a half passed), this was a noticeable increase. The relatively small increase in M's unassisted performance between SA sessions 2 and 3 can be explained with reference to Schmitt and Meara's (1997) finding that there was not much improvement in their participants' WD knowledge within one academic year. What is more, during the SA sessions that followed DA, $\mathrm{M}$ often recalled the meanings of the affixes that were taught to him during the dynamic assessment (e.g., Example 4), but also improved his performance in the use of affixes that he was not taught during the DA.

The analysis of the transcript revealed that, in line with previous studies (e.g., Kozulin, Garb 2002, Teo 2010), in addition to the content knowledge, DA promoted M's use of strategies and knowledge sources. Specifically, owing to the mediation M received during the DA, he started analysing words morphologically and referred to semantics of derivational affixes more frequently than before the DA. The connection found between M's self-reports and the mediation in the DA also suggests that it was dynamic assessment that led to these changes.

That is to say, M learned to analyse words to get their meaning, paying attention to both the affixes and bases, but also realised that syntactic knowledge, while being useful, does not always help. Thus, in addition to learning some suffixes, $\mathrm{M}$ was able to recognise other suffixes, which improved his performance as well.

It is important to emphasise, though, that DA did not result in the emergence of new strategies in M's repertoire - all the strategies and knowledge sources that he used during later SA sessions had already been present during the first SA. What is more, during the later SA sessions, $\mathrm{M}$ successfully used strategies that were not elicited during the DA.

The latter can be interpreted with reference to the model of Tseng et al (2006). The mediation provided to M (Example 4; Table 5) reminded him of the goals by eliciting that he had to pay attention to affixes, thus also helping him to stay concentrated on the tasks. Importantly, at later DA sessions, less mediation was provided, which should have confirmed that the techniques that $\mathrm{M}$ had been using previously were successful and gave him more control in selecting these techniques. This resulted in $\mathrm{M}$ becoming aware of how certain strategies and knowledge sources helped him to improve his performance. In other words the change in his strategy use was qualitative rather than (or in addition to) quantitative (cf. Friedline 2010, Nassaji 2003).

The presence of the interviewer, who urged $M$ to continue thinking aloud, also appeared to guide M's decisions. In Example (1), but also, as demonstrated in Example (6), M appeared to consider the interviewer's utterances as indicative of (in)correctness of his reports. Thus, although being told that the role of the interviewer/researcher during the SA was to learn about M's thinking, M still perceived him as a person whom he could turn to for help. However, in the cases which can 
be interpreted as the interviewer mediating M's performance, this mediation actually resulted in performance which reflected M's WD knowledge more accurately.

Interestingly, following Example (5) (i.e., in the following task), M acknowledged the two mistakes he made in the previous task and corrected them. In other words, should M have been given a possibility to go back to the items, he would have had a perfect score on the meaning recognition task in the last SA session.

Vygotsky's (1978) understanding of Zone of Proximal Development offers an explanation for this. Vygotsky considered that development continues even after it switches from the interpersonal to the intrapersonal plane. An example he provided was a child verbalising his/her own following actions, thus guiding these actions. As the last SA session demonstrated, the DA alone was not enough for $\mathrm{M}$ to learn the correct meanings/use of -able and -ive. However, M's self-mediation resulted in him finally being able to use -able and -ive correctly, which he also confirmed during the final interview. This also suggests that static assessment was not that static for $\mathrm{M}$ after all. I will list this and other limitations in Section 6.

\section{Conclusion}

The present study was aimed at understanding how (if at all) dynamic assessment can promote the development of L2 English word derivational knowledge. The initial hypothesis was that DA should promote the use of certain strategies and increase the participant's overall self-regulatory capacity.

The results spoke in favour of the hypothesis. This is not to say that M did not have access to these strategies and knowledge sources prior to the DA. However, because of the DA, M started using certain strategies more frequently and learned which techniques helped him to solve the tasks requiring demonstration of L2 English WD knowledge, which generally allowed him to use these techniques in proper contexts.

These findings have several implications. First of all, they suggest that adapting feedback to learners' performance can promote their L2 English word derivational knowledge, making their learning more strategic. Furthermore, the study exemplifies what a dynamic test of WD knowledge can look like, which has implications both for test designers and for further research, including, but not limited to, quantitative studies aiming at establishing the effectiveness of DA in promoting learners' WD knowledge.

This said, the study has some limitations. Above all, as with all case studies, the findings lack generalisability. Further research should be conducted to confirm or disprove the findings of the present study. The second limitation arises due to the method selected for the study. Both M's thinking aloud (cf. Bowles 2010) and the interviewer's intervention, however small, mediated M's SA performance. Thus, it is not possible, for example, to ascertain whether M's performance would be the same had he not been thinking aloud. On the other hand, limiting the data to interviews (i.e., a retrospective method) only would make the results less reliable, due to the lack of methodological triangulation. What is more, the study, above all, aimed at establishing how DA changed the way $\mathrm{M}$ approached the tasks rather than calculating reliable scores across the SA sessions. The last limitation arises from the difference 
in the task types and the modality of different DA sessions. The tasks in the humanmediated and the computerised DA were different. Therefore, although M required less help during the computerised DA, it cannot be assumed that it was only because of the development of his WD knowledge. Moreover, the modality of the assessment was different. Thus a definite conclusion cannot be made in this regard.

Despite these limitations, it is hoped that the study produced interesting insights into the development of L2 English word derivational knowledge and ways that dynamic assessment can guide this development.

\author{
Transcription symbols \\ Text originally in English \\ Text stressed word or a part of it \\ $\uparrow \quad$ noticeably rising intonation \\ ((text)) non-verbal behaviour, e.g., laughter, gestures, etc. \\ (.) pause of 0.2 seconds or less \\ (o.o) timed pause \\ : $\quad$ elongation of the preceding sound \\ - $\quad$ utterance is cut off \\ ${ }^{\circ}$ text ${ }^{\circ} \quad$ uttered in a noticeably quieter, softer voice \\ [text] comment
}

\title{
References
}

ATLAS.ti. Version 5.o. [Computer software] 2004. Berlin: Scientific Software Development. Bauer, Laurie; Nation, I. S. Paul 1993. Word families. - International Journal of Lexicography, 6 (4), 253-279. http://dx.doi.org/10.1093/ijl/6.4.253

Bowles, Melissa A. 2010. The Think-Aloud Controversy in Second Language Research. Routledge.

Council of Europe 2001. Common European Framework of Reference for Languages: Learning, Teaching, Assessment. [Electronic version.] http://www.coe.int/t/dg4/linguistic/ Source/Framework en.pdf (30.6.2015).

Dörnyei, Zoltán 2005. The psychology of the Language Learner: Individual Differences in Second Language Acquisition. Mahwah, NJ: Erlbaum.

Friedline, Benjamin E. 2011. Challenges in the Second Language Acquisition of Derivational Morphology: From Theory to Practice. Doctoral dissertation. University of Pittsburgh.

Kozulin, Alex; Garb, Erica 2002. Dynamic assessment of EFL text comprehension. School Psychology International, 23 (1), 112-127. http://dx.doi.org/10.1177/ 0143034302023001733

Leontjev, Dmitri 2014. The Effect of Automated Adaptive Corrective Feedback: L2 English questions. - APPLES: Journal of applied language studies, 8 (2), 43-66. http://apples. jyu.fi/article/abstract/301 (30.6.2015).

Leontjev, Dmitri (forthcoming). L2 English Derivational Knowledge: Which Affixes Are Learners More Likely to Recognise? - Studies in Second Language Learning and Teaching.

Leontjev, Dmitri; Huhta, Ari; Mäntylä, Katja (forthcoming). Word derivational knowledge and writing proficiency: How do they link?

Mäntylä, Katja; Huhta, Ari 2013. Knowledge of word parts. - J. Milton, T. Fitzpatrick (Eds.), Dimensions of Vocabulary Knowledge. Basingstoke, UK: Palgrave, 45-59.

Nakayama, Natsue 2008. Effects of Vocabulary Learning Using Affix: Special Focus on Prefix. http://www.kyoai.ac.jp/college/ronshuu/no-08/nakayama.pdf (30.6.2015). 
Nassaji, Hossein 2003. L2 vocabulary learning from context: Strategies, knowledge sources, and their relationship with success in L2 lexical inferencing. - TESOL Quarterly, 37 (4), 645-670. http://dx.doi.org/10.2307/3588216

Nation, I. S. Paul 2001. Learning Vocabulary in Another Language. Cambridge: Cambridge University Press. http://dx.doi.org/10.1017/CBO9781139524759

O’Malley, Michael J.; Chamot, Anna U. 1990. Learning Strategies in Second Language Acquisition. New York: Cambridge University Press. http://dx.doi.org/10.1017/ CBO9781139524490

Oxford, Rebecca L. 1990. Language Learning Strategies: What Every Teacher Should Know. New York: Newbury House.

Poehner, Matthew E. 2008. Dynamic Assessment: A Vygotskian Approach to Understanding and Promoting L2 Development. Berlin: Springer. http://dx.doi. org/10.1007/978-0-387-75775-9

Poehner, Matthew E.; Lantolf, James P. 2013. Bringing the ZPD into the equation: Capturing L2 development during computerized dynamic assessment (C-DA). - Language Teaching Research, 17 (3), 323-342. http://dx.doi.org/10.1177/1362168813482935

Põhikooli riiklik õppekava õigusakt (2010); Lisa 2. [Basic School National Curriculum Act: Annex 2.]. Pub. L. No. RT I 2010, 6, 22. https://www.riigiteataja.ee/aktilisa/1281/2201/0017/13275423.pdf (2.7.2015).

Rose, Heath 2012. Reconceptualizing strategic learning in the face of self-regulation: Throwing language learning strategies out with the bathwater. - Applied Linguistics, 33 (1), 92-98. http://dx.doi.org/10.1093/applin/amro45

Schmitt, Norbert; Meara, Paul 1997. Researching vocabulary through a word knowledge framework. - Studies in Second Language Acquisition, 19 (1), 17-36. http://dx.doi. org/10.1017/S0272263197001022

Swain, Merrill 1998. Focus on form through conscious reflection. - C. Doughty, J. Williams (Eds.), Focus on Form in Classroom Second Language Acquisition. New York: Cambridge University Press, 64-81.

Teo, Adeline 2012. Promoting EFL students' inferential reading skills through computerized dynamic assessment. - Language Learning \& Technology, 3, 10-20. http://llt.msu. edu/issues/october2012/action.pdf(20.9.2014).

Tseng, Wen-Ta; Dörnyei, Zoltán; Schmitt, Norbert 2006. A new approach to assessing strategic learning: The case of self-regulation in vocabulary acquisition. - Applied Linguistics, 27 (1), 78-102. http://dx.doi.org/10.1093/applin/amio46

Tulving, Endel; Kroll, Neal 1995. Novelty assessment in the brain and long-term memory encoding. - Psychonomic Bulletin \& Review, 2 (3), 387-390. http://dx.doi. org/10.3758/BFo3210977

Vygotsky, Lev S. 1978. Mind in Society: The Development of Higher Psychological Processes. Cambridge, MA: Harvard University Press.

Dmitri Leontjev (University of Jyvaskyla, Centre for Applied Language Studies) P.O. Box 35, FI-40014 University of Jyvaskyla, Finland

dmitri.leontjev@jyu.fi 


\section{Appendix. Static assessment tasks}

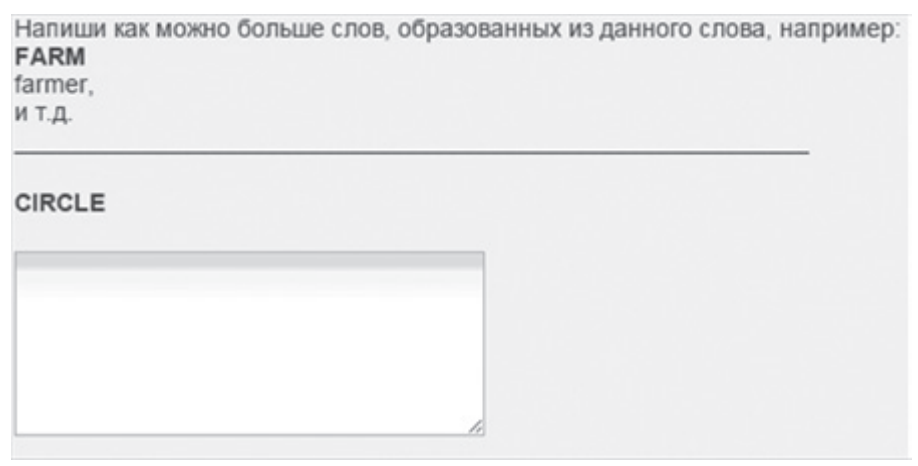

Figure 2.1. Sample item from the free production task

Напиши части речи, образованные от данного тебе слова, например:

FARM

существительное: farmer

\section{INTERACT}

Существительное (напр., farmer):

Глагол (напр., go):

Прилагательное (напр., good):

Figure 2.2. Sample item from the metalinguistic prompts task

Закончи выделенные слова, в следующих предложениях, дописав к ним подходящую приставку или суффикс

1. She could bourble animals very well because she was a good $\square$ bourble $\square$. человек, который выполняет работу, описанную виделенным словом)

2. She is usually a rather spalk player, and today, too, she played very spalk (= играл так, как описывает выделенное слово)

Figure 2.3. Sample item from the non-word affix elicitation task

\begin{tabular}{|l|l|l|l|l|l|l|l|l|l|l|l|l|l|}
\hline NON & MID & INTER & ANTI & EX & COUNTER & BI & EN & DE & IL \\
\hline IR & POST & IM & PRE & IN & MIS & UN & RE \\
\hline
\end{tabular}

Figure 2.4. Sample item from the prefix elicitation task 


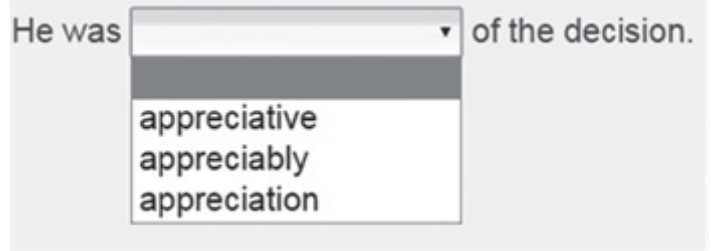

Figure 2.5. Sample item from the grammar recognition task

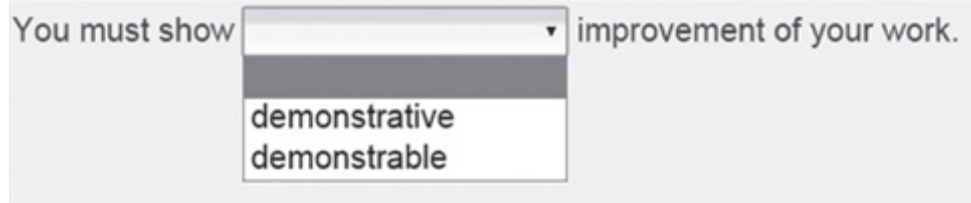

Figure 2.6. Sample item from the meaning recognition task
Kids are very suggestible
often give advice to other people
are very similar to their parents
can be easily changed by others

Figure 2.7. Sample item from the passive recognition of the meaning task 


\section{SÕNATULETUSE OSKUSTE DÜNAAMILINE HINDAMINE: ÜHE ÕPILASE ARENGU JÄLGIMINE}

\section{Dmitri Leontjev}

Jyväskylä Ülikool

Uurimuse eesmärk on süvendada arusaamist sellest, kuidas dünaamiline hindamine võimaldab arendada õppija sõnatuletusoskusi. Õppija sõnatuletusteadmiste arengut võrreldi enne ja pärast hindaja- ja arvutipõhist dünaamilist hindamist. Uurimus keskendub õppija strateegiate ja teadmiste allikate kasutusele. Peamiste uurimisvahenditena rakendati valjusti mõtlemise protokolle ja intervjuud. Õppija arengudünaamika jälgimiseks oli hindaja ja arvutipõhise hindamise vahel pooleteistaastane paus. Analüüs osutas, et õppija mitte ainult ei hakanud rakendama hindamise käigus kasutatud strateegiaid, vaid muutus keeleloomes ka üldiselt edukamaks. Seega aitas dünaamiline hindamine süvendada õppija sõnatuletusteadmisi ja arendada strateegiapädevust.

Võtmesõnad: teise keele omandamine, sotsiokultuuriline teooria, vahendamine, tuletusstrateegiad, teadmiste allikad, eneseregulatsioon, inglise keel 